\title{
Mavi Okyanus Stratejisi ve Sağlık Sektörü Uygulamaları Üzerinde Bir Çalışma
}

\author{
Uğur UĞRAK b,c, Özgür UĞURLUOĞLU d
}

\section{Özet}

Mavi okyanus stratejisi ortaya atıldığı günden beri hem iş dünyası hem de akademik camia tarafından yoğun ilgi görmüştür. Özellikle mavi okyanus stratejisinin yeni talep alanları oluşturarak, rekabeti anlamsız bırakma önerisi nedeniyle, farklı endüstriler tarafından başarıyla uygulanmıştır. Pek çok endüstride olduğu gibi, yoğun rekabet ortamının olduğu sağllk sektörü mavi okyanus stratejisinin uygulanabileceği sektörlerden biri olabilir. Bu çalışma uluslararası literatür taraması yaparak, "mavi okyanus stratejisinin" kavramsal çerçevesini ve bu stratejinin sağlık sektöründe uygulanabilirliğine yönelik bir bakış açısını ortaya koymayı hedeflenmektedir. Yapılan literatür taramasında, mavi okyanus stratejisinin birçok sektörde başarı ile uygulandığ görülmüştür. Sağlık sektöründeki uygulamalarının henüz sınırlı olmasına rağmen, çeşitli sektörlerdeki başarısına dayanarak mavi okyanus stratejisinin sağlık hizmet alanında uygulanma potansiyelinin olduğu değerlendirilmektedir
Anahtar Kelimeler

Mavi Okyanus Stratejisi

Sağlık Sektörü

Sağlık Hizmetleri

Makale Hakkında

Geliş Tarihi: 06.11.2019

Kabul Tarihi: 10.06.2020

Doi: 10.18026/cbayarsos.643784

\section{A study on Blue Ocean Strategy and Health Sector Practices}

\begin{abstract}
Since blue ocean strategy was put forward, it has been intensely interested by both business world and academic community. Particularly, because of blue ocean strategy's offer to make competition irrelevant by creating untapped demand, blue ocean strategy has been successfully applied by various industries. As in many industries, health sector, in which a highly competitive environment is in effect can be one of the sectors in which blue ocean strategy can be applied. This study, conducting international literature survey, aim at presenting conceptual framework of blue ocean strategy and a perspective for applicability of blue ocean strategy in health sector. In literature survey, it was seen blue ocean strategy was successfully applied across various sectors. Though practices of the blue ocean strategy in health sector have been limited yet, depending on its success in different sectors, it is considered to have potential to be applied in health care sector.
\end{abstract}

Keywords

Blue Ocean Strategy

The Health Sector

Health Services

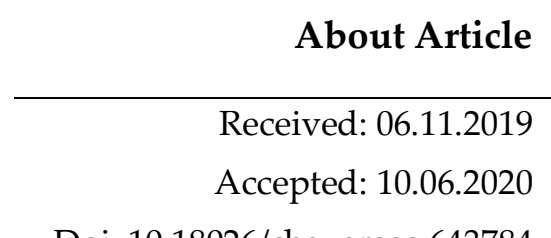

Doi: $10.18026 /$ cbayarsos.643784

b İletişim Yazarı: ugrakugur@gmail.com

c Dr., Gülhane Eğitim ve Araştırma Hastanesi / ANKARA, https://orcid.org/0000-0002-6043-835X

d Prof. Dr., Hacettepe Üniversitesi, İktisadi ve İdari Bilimler Fakültesi, Sağlık Yönetimi Bölümü/ ANKARA, https://orcid.org/0000-0002-9453-9925 


\section{Giriş}

Stratejik yönetim, uzun dönemde işletmenin yaşamını sürdürmesi ve rekabet üstünlüğü sağlamasını amaçlayan bir yönetim tarzı olarak değerlendirilmektedir (Ülgen ve Mirze, 2013). Tanımdan da anlaşılacağı gibi işletmeler rakiplerine üstünlük sağlamak için stratejik yönetim sürecini kullanılmaktadır. Stratejik yönetim sürecinde kullanılan çok sayıda metot ve analiz yöntemi mevcuttur. Özellikle 2004'yılında Chan Kim ve Mauborgne tarafından ortaya atılan "mavi okyanus stratejisi" oldukça ilgi toplamıştır. Yazarların yayınladıkları "How to Create Uncontested Market Space and Make the Competition Irrelevant" isimli kitap kırk üç dile çevrilmiş ve üç buçuk milyon kopyanın üstünde satmıştır. Yazarlar dünyanın ilk elli yönetim gurusu listesinde ikinci olarak sıralanmışlardır (Zemsky, 2015). "Mavi okyanus strateji" rekabeti anlamsız bırakarak yeni talep alanları oluşturma önerisi ile hem iş hem de akademik camia tarafından oldukça ilgi görmüştür. Bu yönüyle bu stratejinin rekabetin yoğun olduğu sağlık sektöründe uygulanabileceği düşünülmektedir.

Sağlık hizmet sektörü hızla gelişen ve rekabet kurallarının hâkim olduğu "kırmızı okyanus" piyasalarından biridir. El değmemiş piyasalara ulaşmayı vadeden "mavi okyanus stratejisi" sağlık kurumlarında rekabeti anlamsız bırakarak kârlı çalışmasını olanaklı kılacağı değerlendirilmektedir. Konu ile ilgili olarak yapılan literatür taramasında Türkiye'de mavi okyanus stratejisine yönelik olan çalışmaların oldukça sınırlı olduğu tespit edilmiştir (Barutçu, 2014; Cengiz, 2013). Ayrıca Türkiye'de sağlık sektöründe mavi okyanus stratejisinin uygulamasına yönelik bir çalışmaya rastlanılmamıştır. Türkiye'de mavi okyanus stratejine yönelik çalışmaların çok sınırlı olması bu çalışmanın çıkış noktasını oluşturmaktadır. Bu çalışma dünyada göreceli olarak yeni bir stratejik akım olan "mavi okyanus stratejisini" incelemeyi ve uluslararası literatür taraması da yaparak bu stratejinin uygulanabilirliğine yönelik verileri derlemeyi hedeflenmektedir. Özellikle dünyada hızla büyüyen bir sektör olan sağlık hizmet sektöründeki mavi okyanus stratejisi uygulamalarını uluslararası literatürde araştırarak, stratejinin sağlık hizmet sektöründeki kullanım potansiyelinin incelenmesi amaçlanmıştır. Uluslararası literatürde konu ile ilgili yapılan taramalarda "mavi okyanus stratejisi", "sağllk hizmetleri yönetimi" "sağlık hizmetleri", "hastane" ve "sağlık" anahtar kelimeleri ve kombinasyonları kullanılarak yapılan taramalar sonucunda elde edilen kaynaklar çalışmanın amacı kapsamında değerlendirilmiştir.

\section{Kavramsal Çerçeve}

Bu bölümlde mavi okyanus stratejisin kullanılan temel kavramalar ve araçlar hakkında genel bilgiler verilecektir

\section{Kirmızı Okyanus}

İş dünyası temel olarak iki tür alandan oluşmaktadır. Bu alanlar kırmızı ve mavi okyanuslar olarak düşünülmektedir. Kırmızı okyanus mevcut piyasa olarak adlandırılan tüm endüstrileri temsil etmektedir (Kim ve Mauborgne, 2004; 2005a; 2005b; 2005c). Kırmızı okyanusta endüstri sınırları tanımlamış ve kabul edilmiştir. Rekabet kuralları iyi anlaşılmıştır. Kırmızı okyanusta işletmeler mevcut talepten daha büyük pay alabilmek için rakiplerini alt etmeye çalışmaktadırlar. Bu okyanus giderek kalabalıklaştığı için kâr ve büyüme elde etme olasılığı giderek azalmıştır. Sonuç olarak artan rekabet bu suları bir nevi kanlı okyanus haline getirmiştir (Kim ve Mauborgne, 2004; 2005a). 
Kırmızı okyanusta rakipleri alt ederek başarılı bir şekilde yol almak her zaman önemli bir unsurdur ve iş hayatının bir gerçeği olarak da kalacaktır (Kim ve Mauborgne, 2005a; 2005b). Ancak, 21. yüzyılda teknolojinin ilerlemesi sayesinde ürün çeşitliliği artmış, çok çeşitli ürünler piyasaya sürülmeye başlamıştır. Ticari bariyerlerin ortadan kalkması ile birlikte, ürün ve ürün fiyatları global olarak aynı anda ulaşılabilir olmuştur. Tekel ortadan kalkmaya başlamıştır. Bunun yanında talepte artış yok denecek kadar azdır. Bu durum ürünlerin metalaşması, fiyat savaşlarının artması ve kar marjının küçülmesini kaçınılmaz kılmaktadır (Kim ve Mauborgne, 2004; 2005a). Sonuç olarak arz talebi aşmıştır ve işletmelerin rekabet ettikleri var olan endüstrilerin daha ötesine gitmeleri gerekmektedir (Kim ve Mauborgne, 2005b).

Kırmızı okyanusta hayatta kalabilmek için, şirketler stratejilerini rekabet avantajı sağlamak üzerine odaklamaktadırlar, sıklıkla rakiplerin ne yaptığını değerlendirmekte ve karşılığında daha iyiye ulaşmaya çalışmaktadırlar. Piyasadan büyük payı kapmak bir nevi sıfır toplamlı bir oyun gibidir. Bir şirketin kazancı diğerinin kaybı anlamına gelmektedir. Bu nedenle rekabet mevcut piyasa alanını paylaşmaya odaklı stratejik değişkenlerin tanımlanması olarak kullanılmaktadır. Açıklamalardan anlaşılacağı gibi stratejinin temelinde rekabet yatmaktadır. Ancak durum böylemi olmalı midır? (Kim ve Mauborgne, 2004).

Chan Kim ve Mauborgne'nin (2004; 2005b) yaptığ1 araştırma bunun tersini göstermektedir. Rekabet önemlidir ancak rekabet stratejisine odaklanan işletmeler daha önemli olan stratejik boyutları kaçırmaktadırlar. Bu boyut rekabet etmek değil, rekabetin olmadığı ve araştırmacıların "mavi okyanus" olarak adlandırdıkları yeni piyasa alanları oluşturarak rekabeti önemsiz kılmayı içermektedir.

\section{Mavi Okyanus}

Mavi okyanus günümüzün bilinen piyasalarda var olmayan ve rekabet tarafından bozulmamış olası tüm olası endüstrileri ifade etmektedir (Kim, 2008; Kim ve Mauborgne, 2004; 2005a; 2005b; 2005c). “Mavi okyanus" terimi, geniş, derin ve henüz keşfedilmemiş daha büyük potansiyelli piyasa alanını tanımlayan bir benzetmedir (Kim ve Mauborgne, 2005b). Mavi okyanus terimi yeni bir kavram olmasına rağmen, geçmişten günümüze uzanan bir olgudur (Kim, 2008; Kim ve Mauborgne, 2005c). Geçmişe baktığınızda bu teori ortaya koyulmadan önce mavi okyanus uygulaması olarak nitelendirebileceğimiz başarılı girişimler mevcuttur (Nicolas, 2011). Hatta tarih, piyasaların mavi okyanus olarak oluştuğunu zamanla rekabet, fazla arz ve metalaşma nedeni ile kırmızıya dönüştüğünü kanıtlamıştır (Kim, 2008).

Yüz yıl öncesine bakıldığında bugün bilinen endüstrilerin birçoğunun var olmadığı görülmektedir. Otomobil, havacılık, petrokimya, müzik kayıt endüstrileri bunlardan sadece birkaçıdır. Bu tarihten sadece otuz yıl geriye gidildiğinde ise multi-milyar dolarlık endüstriler ortaya çıkmaktadır. Örneğin; ortak fonlar, cep telefonları, kargo şirketleri, video oyun endüstrisi bunlardan sadece birkaç tanesidir. Bu bağlamda zamanda yirmi yıl ileriye yönelik bir öngörü ortaya konulursa, bilinmeyen birçok yeni endüstrinin ortaya çıacağ düşünülmektedir (Kim ve Mauborgne, 2005c).

\section{Neden Mavi Okyanus?}

Mavi okyanusta çok sayıda kârlı ve hızlı büyüme fırsatı bulunmaktadır. Mavi okyanus oluşturma iki yolla yapılabilmektedir. Tamamen yeni bir endüstri oluşturarak yapılabilmekte, ya da çoğu durumda olduğu gibi işletmeler mevcut kırmızı okyanusun sınırlarını değiştirerek bu okyanus içinde bir mavi okyanus oluşturabilmektedirler (Kim ve Mauborgne, 2004; 2005a). 
Chan Kim ve Mauborgne (2005a; 2005b; 2005c) 108 şirket üzerinde bir çalışma yürütmüşlerdir. Şekil 1'deki görüldüğü gibi bu çalışmada işletmelerin \%86'sı mevcut kırmızı okyanus içindeki var olan endüstrinin bir uzantısı olarak girişimde bulunurken, $\% 14^{\prime}$ ü ise yeni piyasaları veya yeni mavi okyanusları hedeflemişlerdir. Kırmızı okyanusta girişimde bulunan işletmeler toplam gelirin \%62'sini oluştururken, toplam kârın sadece \%39'unu ortaya koyabilmişlerdir. Mavi okyanusa yatırım yapan \%14 ise toplam gelirin \%38'ini oluştururken, toplam kârın şaşırtıcı bir biçimde \%61'ini ortaya koymuşlardır. Görüldügü gibi iş girişimlerine yapılan toplam yatırımlar göz önüne alındığında, mavi okyanus oluşturmanın performans farkı açiktır.

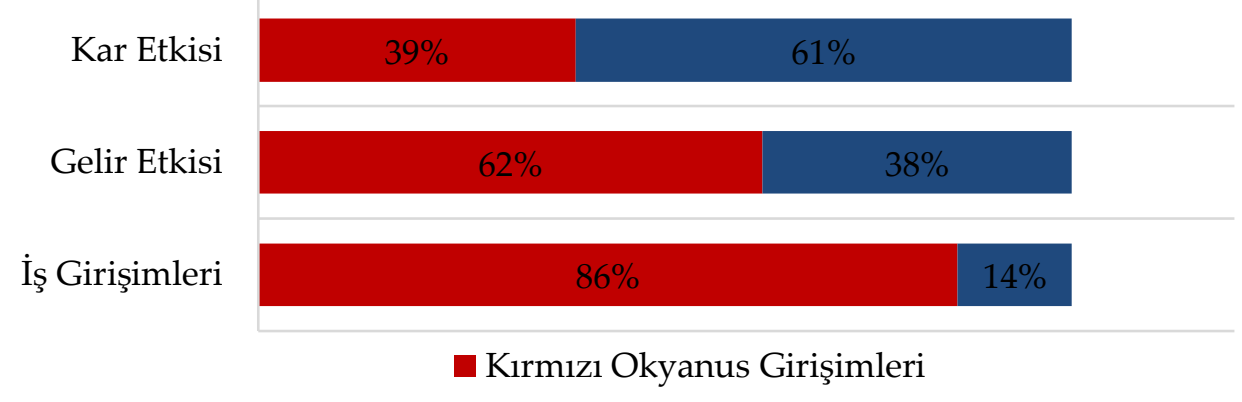

Şekil 1. Mavi Okyanus Stratejisinin Kar ve Büyüme Sonuçları

Kim, W. C., and Mauborgne, R. (2005a). Value innovation: a leap into the blue ocean. Journal of Business Strategy, 26(4), 22-28.

$\mathrm{Bu}$ verilere rağmen neden yapılan iş girişimlerinin büyük bir kısmı kırmızı okyanusta yapılmıştır. Bu kısmen strateji dilinin askeri referanslarla dolu olması ile açıklanabilmektedir. Bu yönü ile bakıldığında kırmızı okyanustaki strateji tamamen rekabete yöneliktir. Tamamen rekabete odaklanan işletmeler, akademisyenler ve danışmanlar iki çok önemli noktayı göz ardı etmektedirler. İlki rekabetin olmadığı veya çok az olduğu mavi okyanusları bulup geliştirmek, diğeri ise mavi okyanusları kullanıp korumaktır (Kim ve Mauborgne, 2004).

\section{Mavi Okyanus Stratejisine Genel Bakış}

Genellikle bir işletme, stratejisini geliştirirken içinde çalıştığ çevrenin ve endüstrinin mevcut durumunu analiz eder. Daha sonra rekabet içinde olduğu oyuncuların güçlü ve zayıf yönlerini değerlendirerek onları alt edebilecek stratejiler geliştirmeye odaklanır. Bu yaklaşım "yapısalcı" yaklaşım olarak adlandırılmaktadır. Ancak çevre ve endüstri işletmelerin stratejilerini şekillendirmek zorunda değildir. Tarih; çevresi tarafından şekillendirilmekten ziyade çevresini yapılandırabilen strateji örnekleri ile doludur. Mavi okyanus stratejisi işletmelerin kendi içinde bulundukları endüstrileri yeniden yapılandırmalarına yardım edebilir, yapı ve strateji dizgisini tersine çevirebilir. Bu tür strateji oluşumu ise "yeniden yapılandırıcı" strateji olarak adlandırılmaktadır (Kim ve Mauborgne, 2009).

Belirlenmiş yapı ve piyasa sınırları sadece yöneticilerin akıllarındadır. "Yeniden yapılandırıcı" görüşe sahip olanlar mevcut piyasa yapısının düşüncelerini sınırlandırmalarına izin vermezler. Yeniden yapılandırıcı düşünce için, ekstra talep el değmemiş bir şekilde bir yerlerdedir. Asıl problem de onun nasıl oluşturulacağıdır. Bunu yapmak için, odak arzdan talebe, rekabetten rekabeti arkada bırakmaya yoğunlaşmalıdır (Kim ve Mauborgne, 2005b).

Chan Kim ve Mauborgne (2004; 2005a) yüz yıl geriye dönük olan verilerle on yıldan fazla süre ile üç farklı endüstride yaptıkları araştırmada mavi okyanus oluşturmada kullanılan kalıpları 
tespit etmişlerdir. Buna göre insan hayatına yakından dokunan üç endüstri dalında (otomotiv, bilgisayar, sinema) mavi okyanus oluşumunda önemli olan noktaları belirlemişlerdir (Kim ve Mauborgne, 2004).

Chan Kim ve Mauborgne (2004) bu araştırma sonuçlarına göre mavi okyanusların sadece teknolojik yenilikle ilgili olmadığı görüşündedirler. Bazı mavi okyanus oluşumlarında önemli teknolojik gelişmeler yer almıştır ancak bu mavi okyanus oluşumunun tanımlayıcı özelliği değildir. Hatta bu kural teknoloji yoğun endüstrilerde bile geçerlidir. Mavi okyanus oluşturmada kullanılan teknolojilerin çoğu hali hazırda var olan teknolojiler olduğu sonucuna ulaşılmıştır.

Chan Kim ve Mauborgne'nin (2004) araştırmasına göre yaratılan çoğu mavi okyanus işletmelerin faaliyet alanlarının dışında değil, kendi bünyelerinde yaratılmıştır. Sonuç olarak mavi okyanus yaratmak için yerleşik işletme olmak bir dezavantaj değildir. Aynı araştırmasından elde edilen diğer bir bulgu ise mavi okyanus oluşumunu açıklamak için en iyi analiz ünitesinin stratejik hareketler olduğudur. Diğer bir ifade ile mavi okyanus oluşturma sürecindeki marjinal hareketler dizisi ve kararlar mavi okyanus oluşumunu açıklayabilecek en iyi analiz ünitesidir.

Yazarlar ayrıca mavi okyanus yaratmanın marka oluşturmak olduğunu tespit etmişlerdir. Chan Kim ve Mauborgne (2004) araştırmaları kapsamındaki işletmelerin neredeyse hemen hepsi mavi okyanus oluşturmadaki girişimleri ile hatırlanmazlar. Çok az insan Ford'un yaptığı T Modelini bugün bilmektedir, ancak Ford markası halen mavi okyanus girişiminden faydalanmaktadır.

Mavi okyanus stratejisinin sadece büyük işletmelerde değil, küçük ve orta ölçekli işletmelerde de uygulanabileceği düşünülmektedir (Eboreime vd., 2014). Büyük bütçeler mavi okyanus oluşturmada anahtar özellik değildir. Önemli olan doğru stratejik hamleyi yapabilmektir (Kim ve Mauborgne, 2004).

\section{Mavi Okyanus Stratejisinin Köşe Taşı: Değer İnovasyonu}

Mavi okyanus stratejisi, rekabet edilen piyasaya göre daha fazla talebin ve rekabetin anlamsız olduğu yeni piyasa oluşturmanın arkasındaki tutarlı stratejik düşünce olarak tanımlanmıştır (Kim ve Mauborgne, 2004). Mavi okyanus stratejisi geleneksel kuralların aksine karşılaştırma noktası olarak rekabeti asla kullanmamaktadır. Bunun yerine hem kendileri hem de alıcılar için yeni bir değer yaratarak, rekabeti anlamsız bırakmak suretiyle, yeni el değmemiş bir piyasa oluşturmayı hedeflemektedir. Rekabeti anlamsız bırakmak için uygulanan değer yaratma süreci "değer inovasyonu" olarak adlandırılmaktadır (Kim ve Mauborgne, 2005a; 2005c). Geleneksel stratejinin ve mavi okyanus stratejisinin farklılık yaratma yaklaşımları arasındaki temel fark, geleneksel stratejinin farklılığı üretim tabanlı olup, eldeki imkânlarla ne üretebilip ve arz edilebileceği hususu üzerine odaklanırken, mavi okyanus stratejisinin ise talep tabanlı olarak farklılık yaratmaya çalışmasıdır. Mavi okyanus stratejisi bir ürün müşterilere nasıl gerçek bir değer sunabilir sorusuna cevap aramaktadır (Haavisto, 2005).

Temelde işletmelerin müşterilerine önerebileceği üç tür değer vardır. Bunlar endüstriyel etkinlik mantığını kullanarak daha düşük fiyat, uzmanlığı kullanarak ürünlerinin müşteri ihtiyaçlarına uygunluğunu sağlamak ve ağ hizmet mantığını kullanarak müşterilere erişimi kolaylaştırmaktır. Bu üç değerin iki veya daha fazlasını bir arada sunan işletmelerin mavi okyanuslara açılabilme potansiyelleri daha yüksektir (Sheehan ve Vaidyanathan, 2009). 
Değer inovasyonu mavi okyanus stratejinin köşe taşıdır. Mavi okyanus stratejisi piyasadaki rakipleri yenmeye odaklanmaktan ziyade hem alıcı hem de işletme için yeni bir değer yaratarak mevcut piyasa sınırlarının dışına çıkmaya odaklanmaktadır (Kim ve Mauborgne, 2005a; 2005c). Mavi okyanus stratejisinde değer ve inovasyon birbirinden ayrılmaz. Değer inovasyonu hem değere hem de inovasyona aynı anda odaklanmakta ve eşit vurguda bulunmaktadır (Leavy, 2005).

Sadece değere odaklanıldığında bir işletme belki kısa süreliğine kâr elde edebilir, ancak inovasyon olmadan uzun dönemde piyasada tutunamayacaktır (Lainos, 2011). Ayrıca değer inovasyonu rakiplerle rekabeti hedef almaz, onun yerine açtı̆̆ 1 piyasa boşluğunda değer artışı sağlayarak, rakipleri oyun dışı bırakmayı hedeflemektedir (Štverková vd., 2012). Tablo 2'de değer inovasyonunu temel alan mavi ve rekabetçi kırmızı okyanus stratejileri arasındaki farklar gösterilmiştir (Kim ve Mauborgne, 2004; 2005b).

Tablo 2. Kırmızı ve Mavi Okyanus Stratejileri Karşılaştırması

\begin{tabular}{|l|l|}
\hline \multicolumn{1}{|c|}{ Kırmızı Okyanus Stratejisi } & \multicolumn{1}{c|}{ Mavi Okyanus Stratejisi } \\
\hline Mevcut pazar sınırlarında rekabet et. & El değmemiş pazar uzamı yarat. \\
\hline Rekabeti kazan. & Rekabeti konu dışı bırak. \\
\hline Mevcut talepten faydalan. & Yeni talep yarat ve ele geçir. \\
\hline Değer/maliyet ödünleşimini uygula. & Değer/maliyet ödünleşimini kır. \\
\hline $\begin{array}{l}\text { İşletmenin tüm faaliyet sisteminin farklılaştırma } \\
\text { veya düşük maliyet konusundaki stratejik } \\
\text { tercihlerine uygunluğunu sağla }\end{array}$ & $\begin{array}{l}\text { İşletmenin tüm faaliyet sisteminin farklılaştırma } \\
\text { ve düşük maliyet stratejik tercihlerine } \\
\text { uygunluğunu sağla }\end{array}$ \\
\hline Yapısalcı yaklaşım & Yeniden yapılandırıcı yaklaşım. \\
\hline
\end{tabular}

Kim, W. C., \& Mauborgne, R. (2004). Blue ocean strategy. Harvard Business Review.

Büyüme eğiliminde olan endüstrilerde, rekabet genellikle inovasyon üzerine kurulmuş durumdadır (Dehkordi vd., 2012). Mavi okyanusun en önemli özelliği değer ve maliyet değişimine yönelik geleneksel stratejiyi reddetmesidir. Mavi okyanus stratejisi "değer inovasyonu" olarak adlandırılan düşük maliyet ve farklılığı aynı anda elde etme çabasıdır (Kim, 2008). Ancak yapısalcı stratejiye göre işletmeler ya yüksek maliyet ile kaliteli ürün yaratabilirler ya da düşük maliyet ile ortalama bir ürün yaratabilirler (Kim ve Mauborgne, 2004; 2005b; 2009).

Mavi okyanus yaratan işletmelere bakıldığında başarılı işletmelerin hem farklılığın hem de düşük maliyetin peşinde oldukları görülmüştür (Kim ve Mauborgne, 2004). Alıcı değerinin işletmenin sunduğu fiyat ve üründen geldiği, işletmenin kendi için yarattı̆̆1 değerin ise maliyet yapısı, fiyat aracılığı ile oluştuğu göz önüne alındığında, mavi okyanus stratejisi ancak tüm sistem uygulamaları, fiyat ve maliyet aktiviteleri aynı çizgide oldukları zaman başarılabilir (Kim ve Mauborgne, 2004; 2005b). Şekil 2'de görüldüğü gibi mavi okyanus, işletme girişimlerinin maliyetleri düşürdüğü ve alıcı değerini artırdığı noktada meydana gelmiştir (Kim ve Mauborgne, 2004; 2005c). 


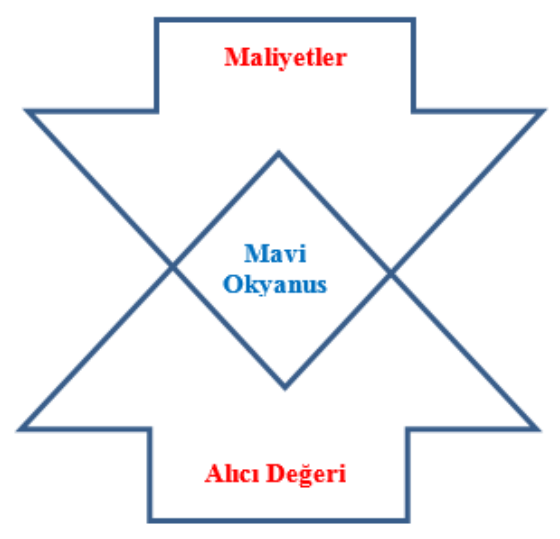

Şekil 2. Farklılaştırma ve Düşük Maliyetin Eş Zamanlı Takibi

Kim, W. C., \& Mauborgne, R. (2004). Blue ocean strategy. Harvard Business Review.

Müşteriler için değer inovasyonunu yaratarak el değmemiş piyasaları arama stratejisi bazı işletmelerde karlı bir büyümeyi sağlamıştır (Parvinen vd., 2011). Sterkova ve arkadaşlarının (2012) yaptığı araştırmada bir uçak firması orta gelir düzeyli bireylere maliyetlerini düşürerek ve yolculara daha ekonomik uçuş sağlayarak hem şirket hem de alıcılar için değer inovasyonu yaratmak sureti ile mavi okyanus yaratmayı başarabilmiştir. Mavi okyanus stratejilerinin başarılı uygulamalarından biride Nintendo firmasına aittir. Wii olarak adlandırdığı yenilikçi oyun kontrolü ile rekabeti anlamsız bırakmada büyük yol almıştır (O'Gorman, 2008).

\section{Mavi Okyanusa Giden Yol}

Mavi okyanus stratejisini temel alan görüşte piyasa sınırları ve endüstri yapısı belirlenmemiştir ve endüstri oyuncularının inanç ve faaliyetlerine göre yeniden yapılandırılabilir (Kim ve Mauborgne, 2005b; 2005c). Bu yapılandırma sürecinde mavi okyanusa ulaşabilmek için işletmelerin kullanabileceği araçlar mavi okyanus stratejisi tasarımcıları tarafından geliştirilmiştir.

Chan Kim ve Mauborgne (2005b) mavi okyanus stratejisinin sistematik ve çalışan bir formülasyonunu geliştirmek amacıyla mavi okyanus arayışında olan işletmeleri ve geliştirilmiş metodolojileri incelemişlerdir. Bu araç ve uygulamaları yaklaşık 20 milyar dolarlık ve yoğun rekabetin olduğu dünya çapındaki şarap endüstrisini kullanarak araştırmışlardır. Bu araç ve uygulamaların en önemli iki tanesi "strateji yelkeni" ve "dörtlü eylem yapısıdır.

\section{Strateji Yelkeni}

Strateji yelkeni cazip mavi okyanusu yaratma sürecinde kullanılan tanımlayıcı bir eylem çerçevesidir. Mevcut piyasadaki oyun durumunu gösterir. Bu da rekabetin şu anda nerede yoğunlaştığının ve piyasada mevcut rekabetçi ürünlerden müşterilerin hangilerini aldığının anlaşılmasında yardımcı olur (Kim ve Mauborgne, 2005b; 2005c).

Bu durum Şekil 3'de Amerika şarap endüstrisi örneklendirilerek gösterilmektedir. Şekildeki yatay eksen rekabet edilen önemli faktörleri gösterirken, dikey eksen ise sunulan faktörlerin miktarını veya yoğunluğunu göstermektedir (Kim ve Mauborgne, 2005c). Chan Kim ve Mauborgne (2005b) araştırmaları kapsamında 1600'den fazla şarap üreticisini müşteri gözünde incelemelerine rağmen, bu üreticilerin strateji eğrilerinin ciddi oranda benzerlik 
gösterdiğini bulmuşlardır. Premium şarap üreticilerinin yüksek fiyata, yüksek kaliteli şarap sunarken, hesaplı şarap üreticilerinin ise daha düşük fiyata orta kalitede şarap sundukları gözlenmektedir (Kim ve Mauborgne, 2005b).

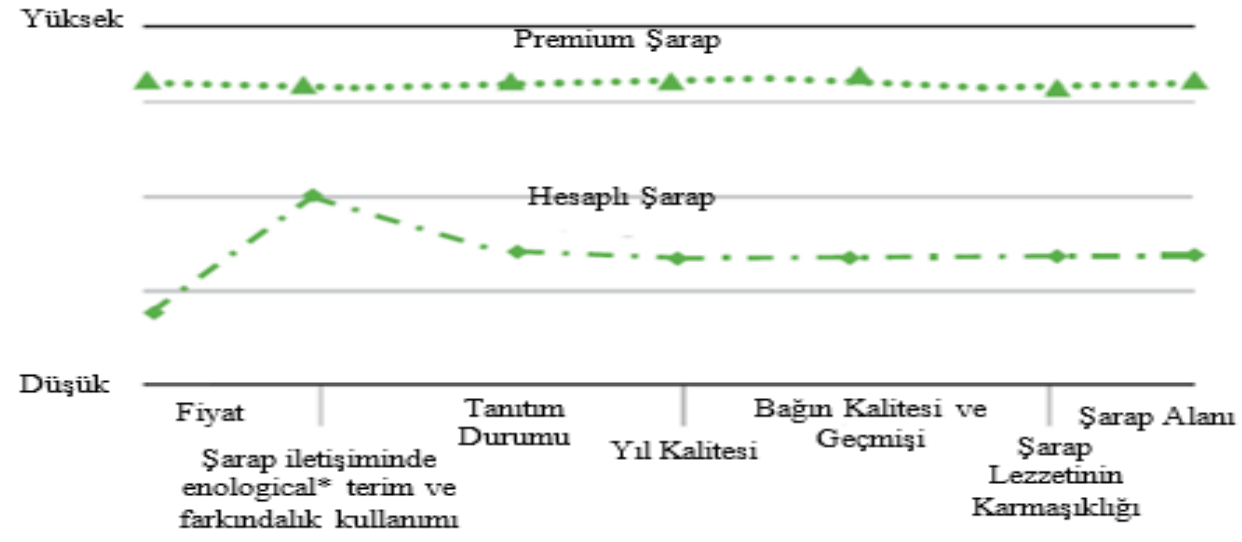

Şekil 3. Strateji Yelkeni

Kim, W. C., \& Mauborgne, R. (2005c). Blue Ocean Strategy, Expanded Edition: How to Create Uncontested Market Space and Make the Competition Irrelevant: Harvard Business Review Press.

Strateji yelkenini temel olarak değiştirmek için, işletmelerin öncelikle strateji odaklarını rekabetten alternatiflere, müşterilerden müşteri olmayan kitleye kaydırmaları gerekmektedir. İşletmeler bunu yaptıkları zaman, endüstrinin odaklandığ $\breve{1}_{1}$ problemi yeniden tanımlayabilirler ve buradan da endüstri sınırları dışında alıcı değer bileşenlerinin nasıl yeniden kurulacağını görebilirler (Kim ve Mauborgne, 2005b).

Şarap üreticileri örneğinde, endüstrideki problem özel durumlar için daha özel şarapların nasıl yaratılacağı sorusudur. Casella Wines firması Yellow Tail isimli şarabı ile alternatiflere bakarak problemleri yeniden tanımlamıştır. Her gün için içimi kolay şarap nasıl yapılır sorusunu sormuştur. Bu soruyu, odağını alternatiflere çevirerek şarap talebinin üç katına denk gelen ve sadece rekabete odaklanan endüstri tarafından göz ardı edilmiş olan bira ve hazır koktail tüketicilerine çevirerek sorabilmiştir. Aynı şirket Amerikan toplumunun çoğu için şarabın aşırı formal ve iddialı olduğunu ayrıca firmaların üstünlük sağlamak için yarıştığı şarabın tadındaki karmaşıklığın ortalama bireyler için lezzet zorluğu oluşturduğu sonucuna ulaşmışlardır. Bu bakış açısı ile Casella Wine mavi okyanusları keşfetmeye hazır hale gelmiştir (Kim ve Mauborgne, 2005b).

Yukardaki örnekten de anlaşılacağı üzerine strateji yelkeni temel olarak üç unsuru vurgulamaktadir.

a. Endüstrideki rekabeti etkileyen faktörleri açıç̧a tanımlayarak endüstrinin strateji profilini ortaya koymaktadır.

b. İşletmelerin hangi faktörlere stratejik olarak yatırım yaptıklarını tanımlayarak, mevcut ve potansiyel rakiplerin strateji profillerini göstermektedir.

c. İşletmenin hangi stratejik faktöre nasıl yatırım yaptığını ve gelecekte nasıl yatırım yapacağını tanımlayan değer eğrisini ortaya koymaktadır (Kim ve Mauborgne, 2005c). 


\section{Dört Eylem Yapısı}

Chan Kim ve Mauborgne (2005c) yeni değer eğrisi oluşturma sürecinde alıcı değer bileşenlerini yaratmak için dört eylem yapısını geliştirmişlerdir. Bu yapı mevcut potansiyeli geliştirmek ve yeni yaratıc fikirlerle ortaya çıkmak için uygulanmaktadır (Rawabdeh vd., 2012). Şekil 3'te görüldüğü üzere dörtlü eylem yapısı endüstrinin stratejik mantığını ve iş modelini sorgulamakta, aynı zamanda aşağıdaki hususları hedeflemektedir;

a. Endüstrinin gereksiz olarak rekabet ettiği faktörleri elimine etmeyi,

b. İşletmelerin rekabet esnasında rakiplerini alt edebilmek için ürün ve hizmetleri gereğinden fazla sunup sunmadıklarını belirlemeyi,

c. Müşterilerin piyasa şartları nedeniyle taviz vermek zorunda oldukları değerleri belirlemeyi,

d. İşletmelere alıcılar için yeni değer kaynakları bulmalarına, yeni talep oluşturmalarına ve endüstri fiyat stratejisini değiştirmelerine yardımcı olmayı hedeflemektedir (Kim ve Mauborgne, 2005b; 2005c).

İlk iki husus maliyetleri düşürmeyi hedeflerken, diğer iki husus alıcı değerini yükseltmeyi ve yeni talep yaratmayı amaçlamaktadır (Kim ve Mauborgne, 2005b; 2005c). Ayrıca dört eylem yapısı yeni değer eğrisi oluşturma sürecinde bu dört hususa göre hareket etmektedir (Rawabdeh vd., 2012).

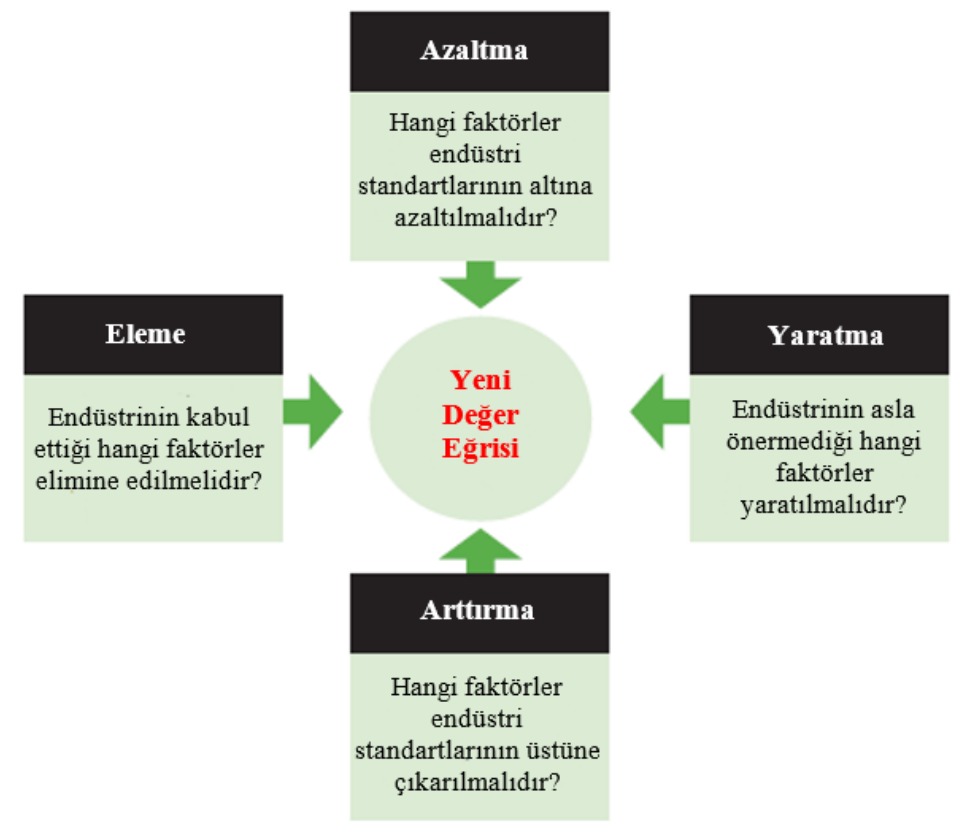

Şekil 4. Dört Eylem Yapısı

Kim, W. C., \& Mauborgne, R. (2005b). Blue ocean strategy: from theory to practice. California Management Review, 47(3), 105-121.

Bir şirket dörtlü eylem yapısını strateji yelkenine uyguladığı zaman, eski algılanan gerçeklere yeni bir bakış açısı ile bakacaktır. Şekil 5'de görüldüğü gibi Casella Wines, Yellow Tail isimli markası ile yeni bir mavi okyanus yaratmıştır. İki yıl içinde Yellow Tail Amerika ve Avusturalya şarap endüstrisinde tarih boyunca en hızlı büyüyen marka olmuştur (Kim ve Mauborgne, 2005b). 


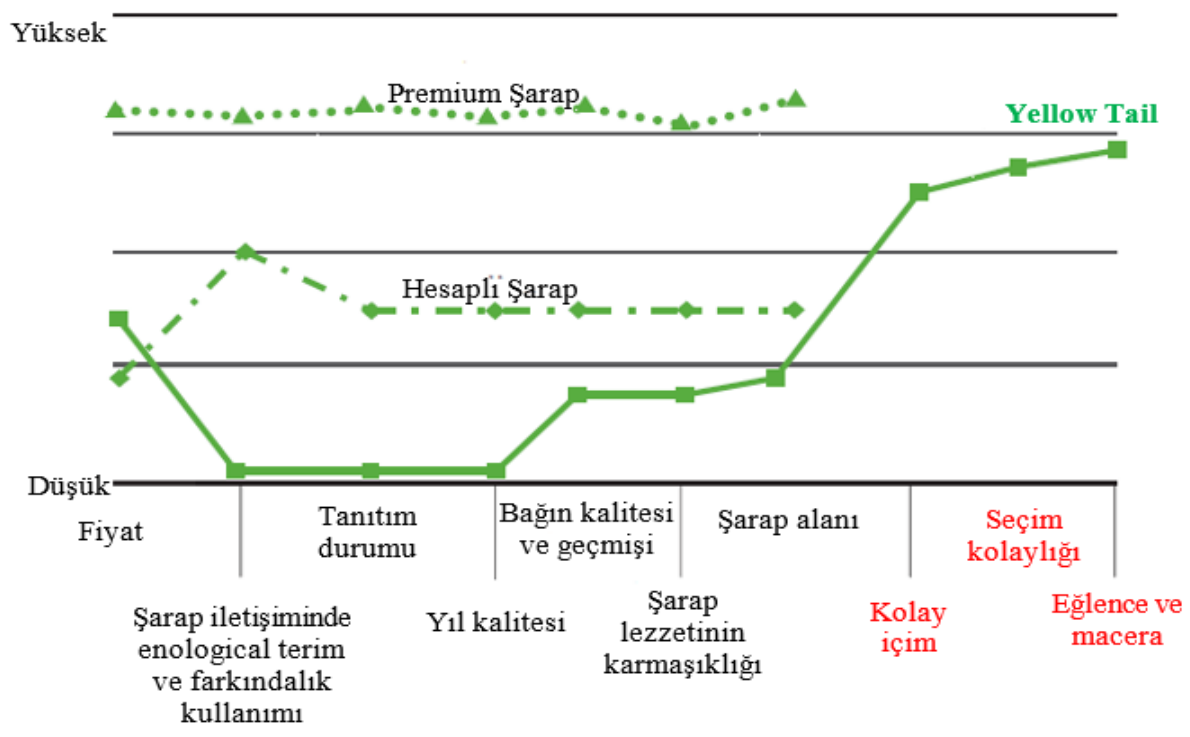

Şekil 5. Strateji Yelkeni (Yellow Tail)

Kim, W. C., \& Mauborgne, R. (2005c). Blue Ocean Strategy, Expanded Edition: How to Create Uncontested Market Space and Make the Competition Irrelevant: Harvard Business Review Press.

Şekil 4'de baktığımızda Yellow Tail marka eğrisinin binlerce şirketin eğrisinden çok farklı bir seyir izlediğini ve hangi faktörlerde farklılık yaptığını (azaltma, arttırma, eleme, yaratma) görülmektedir (Kim ve Mauborgne, 2005b). Casella'nın Yellow Tail markası ile dört eylem yapısı aracılığı ile yaptığı farklılıklar sonucunda alıcı değerinde ciddi bir atılım yapmayı başarmıştır.

\section{Mavi Okyanus Stratejisinin Formülasyonu ve Yürütülmesi}

Mavi okyanus stratejisi risk almak değil, riski azaltmak temeli üzerine kurulu bir stratejidir. Ancak ister kırmızı ister mavi okyanus stratejisi olsun tüm stratejilerde bir risk vardır. Kırmızı okyanusu aşarak mavi okyanusları oluşturmada işletmelerin yüz yüze kalacağı altı adet risk vardır. Bunlar (Kim ve Mauborgne, 2005c);

a. Arama riski: Başarılı mavi okyanusu tanımlayamama riski.

b. Planlama riski: Mavi okyanusa ulaştırabilecek doğrulukta planlama yapamama riski.

c. Kapsam riski: Yeni talebin yaratılacağı piyasayı doğru belirleyememe riski.

d. İş model riski: Doğru stratejik sıralamayı uygulayamama riski.

e. Organizasyon riski: Mavi okyanus stratejisinin uygulama sürecinde organizasyon içinde karşılaşılacak engelleri aşamama riski.

f. Yönetim riski: Mavi okyanus stratejisinin tüm organizasyon çalışanları tarafından benimsenmeme riski.

Mavi okyanus stratejisinde düzgün uygulandı takdirde her riski azaltacak toplam altı tane prensip bulunmaktadır (Kim ve Mauborgne, 2005a). Tablo 4'te görüldügü gibi ilk dört prensip mavi okyanus formülasyon kapsamında iken, son iki prensip yürütme kapsamındadır (Kim ve Mauborgne, 2005c). 


\begin{tabular}{|l|l|}
\hline \multicolumn{1}{|c|}{ Formülasyon Prensipleri } & \multicolumn{1}{c|}{ Her Prensibin Zayıflattığı Risk Faktörü } \\
\hline Piyasa sınırlarını yeniden yapılandırma & Arama riski \\
\hline Sayılara değil, büyük resme odaklanma & Planlama riski \\
\hline Mevcut talebin ötesine ulaşma & Kapsam riski \\
\hline Stratejik sıralamayı doğru uygulama & İş model riski \\
\hline \multicolumn{1}{|c|}{ Uygulama Prensipleri } & Her Prensibin Zayıflattığı Risk Faktörü \\
\hline Önemli organizasyonel engelleri aşma & Organizasyonel risk \\
\hline Yürütmeyi strateji içinde kurma & Yönetim riski \\
\hline
\end{tabular}

Tablo 4. Mavi Okyanus Stratejisinin Altı Prensibi

Kim, W. C., \& Mauborgne, R. (2005c). Blue Ocean Strategy, Expanded Edition: How to Create Uncontested Market Space and Make the Competition Irrelevant: Harvard Business Review Press.

\section{Sağlık Hizmetleri Alanında Mavi Okyanus Stratejisi}

Mavi okyanusun yaratıcıları bu stratejinin sivil toplum kuruluşları dâhil birçok organizasyon tarafından başarılı bir şekilde kullanıldığını ifade etmektedirler (Kim, 2008). Hata Malezya mavi okyanus stratejisini ulusal strateji olarak benimsemiş ve 2020 yılı hedeflerini başarmak amacı ile 2009 yılında Ulusal Mavi Okyanus Zirvesini ilan etmişlerdir (Zemsky, 2015).

Ayrıca mavi okyanus stratejisi turizm sektörü, Business to Business (işletmeler arası) uygulamaları, gıda sektörü ve tedarik zinciri uygulamalarında da başarılı şekilde uygulanmıştır (Čirjevskis vd., 2011; Nasrollahzadeh vd., 2014; Rawabdeh vd., 2012; Tabari vd., 2014). Sağlık sektöründeki uygulamaları ise aşağıda uluslararası literatürdeki örnekleri ile incelenmiştir.

Yapılan literatür taramasında mavi okyanus stratejisine yönelik olarak sağlık hizmet sektöründe yapılan araştırmaların sınırlı olduğu görülmüştür. Ancak mavi okyanus stratejisin kırmızı okyanus kurallarının geçerli olduğu sağlık hizmet sektörü koşulları için de uygun bir strateji olabilir (Collaboration Health Care, 2008). Ayrıca sağlık hizmet sunumunu yeniden tanımlamada ve optimize etmede mavi okyanus stratejisini kullanılabileceği düşünülmektedir. Mavi okyanus stratejisi kullanılarak farklılık yaratılırken, maliyetler de düşürülebilir. Tablo 6’ da görüldüğü gibi dört eylem yapısı bu amaçla kullanılabilir. Gereksiz veya gereğinden fazla kullanımların elenmesi veya azaltılması maliyetleri aşağıya çekerken, önemli görülen girişimlerin artırılması veya yaratılması ise yeni değer yaratmayı ve yeni talep oluşturmayı sağlayabilir (Welch ve Edmondson, 2011). 


\begin{tabular}{|c|c|}
\hline ELEMEK & ARTIRMAK \\
\hline $\begin{array}{l}\text { - } \text { Gereksiz testler } \\
\text { - Önlenebilir hastane yeniden } \\
\text { kabulleri } \\
\text { - Kayıtta kâğıt kullanımı } \\
\text { - Hastane enfeksiyonu }\end{array}$ & $\begin{array}{l}\text { - Kronik hastalık yönetimi } \\
\text { - Bakıma hasta katılımı } \\
\text { - Sağlık geliştirme } \\
\text { - Sağlık taraması }\end{array}$ \\
\hline AZALTMAK & YARATMAK \\
\hline $\begin{array}{l}\text { - } \text { Bakımda parçalamış } \\
\text { - } \text { Tülaşım hastane kabulleri } \\
\text { - } \quad \text { Yüz yüze sunucu viziteleri } \\
\text { - Kalitesiz sağlık bakımı } \\
\text { - Telefon faks kullanımı }\end{array}$ & $\begin{array}{ll}\text { - } & \text { Entegre ağlar } \\
\text { - } & \text { Hasta bakım timleri } \\
\text { - } & \text { Hasta kayıtları } \\
\text { - } & \text { Hasta portalları } \\
\text { - } & \text { Sanal viziteleri } \\
\text { - } & \text { Çoklu erişim noktaları } \\
\end{array}$ \\
\hline
\end{tabular}

Tablo 6. Sağlık Hizmet Sunumuna Yönelik Dörtlü Eylem Yapısı

Welch, S. J., \& Edmondson, B. (2011). Commentary: Applying Blue Ocean Strategy to the foundation of Accountable Care. Am J Med Qual, 27(3), 256-257.

Sağlık hizmetleri alanında ortaya çımaya başlayan mavi okyanus stratejisi örneklerinden birkaçı aşağıda verilmiştir:

a. Ruh sağlığına yönelik tele-tıp: Amerika Birleşik Devletleri (ABD) Houston'da JSA Telepsikiyatri isimli bir şirket uzaktan psikiyatrik değerlendirmelerin yapılabildiği bir metot kullanmaktadır. Bu değerlendirmeler etkili ve yüz yüze hizmet sunumundan daha az maliyetlidir.

b. Yalnız kalınan odalar: ABD Washington'da Everett Bölgesel Sağlık Merkezleri "yalnız kalınan odalar" fikrini uygulamaya koymuştur. Bu uygulamada kalp ameliyatından sonra hastalar hastane yatış sürelerini bir odada yalnız olarak geçirmektedirler. Gerekli ekipmanlar hastanın odasına getirilmektedir (Welch ve Edmondson, 2011). Açık kalp ameliyatı sonrası hastane kalış süreleri 5-7 gün arasında değişmektedir (New Jersey Health Departmant, 2012). Bu uygulamanin sonucunda hasta tatmini artarken, hastane kalış süreleri bir güne kadar düşmüştür (Welch ve Edmondson, 2011).

c. Hello Health: ABD'inde bireylere online ve offline olmak üzere kendilerine yakın olan doktorlarla hizmet sunan bir özel firmadır. Web tabanlı hasta iletişimi, uygulama yönetimi, elektronik sağlık kayıtları bir arada sunulmaktadır. Anlık mesajlaşma ve video vizite de sunulan hizmetler arasındadır.

d. InstyMeds: ABD'nde hastaların reçete edilmiş ilaçlarını tamamen otomatik olarak alabilmelerini sağlayan cihazları üreten bir firmadır. Bu cihazlardan hastalar ilaçlarını banka veya kredi kartı ile 7-24 alabilmektedirler (Welch ve Edmondson, 2011).

Sağlık sektöründe diğer bir örnek Hindistan'da 2010 yılında kurulan Nation Wide Primary Healthcare Services isimli kliniklerin mavi okyanus stratejisi girişimidir. Bu kliniklerin asıl amacı tek merkezli sağlık hizmeti sunarak aile hekimi ile ileri seviye sağlık hizmeti arasındaki boşluğu doldurmaktır (Ahuja, 2010). Bu kapsamda bu sağlık kurumu kamuya açık genel ve uydu klinikler kurmuş, ulusal çapta kullanılabilecek elektronik sağlık kayıt programı geliştirmiş, ev viziteleri, tele konsültasyon, 7-24 doktor yardımı hizmetler sunmaya başlamıştır. Bu klinik aynı anda sağlık planları da sunmaktadır. Yirmi iki aylık uygulama süresince hem kurumsal olarak hem de müşteri açsından sürekli bir büyüme sağlanmıştır. 
Ayrıca abonelerin devamlılı̆̆ını da yaklaşık \%90 oranında tutabilmiştir (Ahuja, 2010). Bu araştırmadan görülebildiği gibi mavi okyanus girişimi kendi endüstri sınırları içindeki bir boşluğu değerlendirme amacı ile uygulanmıştır.

Komphaneg'ta Çin akupunkturu piyasa rekabetinin çok yoğun olduğu bir sektördür ve neredeyse hastanelerin üçte biri akupunktur tedavisi sunmaktadır (Kang ve Li, 2013). Kang ve Li (2013) rekabetin yoğun olduğu bu akupunktur piyasasında en rekabetçi firmaların sahipleri, doktorları ve müşterileri ile derinlemesine görüşme yönetimini kullanarak ve elde ettikleri verilerden yola çıkarak bir anket hazırlamışlardır. Hazırladıkları anketi akupunktur müşterilerine uygulamışlardır. Anketten, derinlemesine görüşme metodundan ve internetten elde etikleri verilerden yola çıkarak mavi okyanus stratejisini Jiankag Kliniğine uygulamışlardır (Kang ve Li, 2013). Mavi okyanus stratejisi araçlarından dört eylem yapısı uygulaması sonucunda aşağıdaki hususlar kliniğe önerilmiştir;

a. TV ve gazete reklamlarının elenmesi,

b. El ilanı ve kartvizit dağıtımının azaltılması,

c. Doktor ve hasta iletişiminin daha iyi olabilmesi iyi sevide tercüman sayısının artırılması,

d. Qigong ve diğer geleneksel Çin sağlık aerobiklerinin artırılması,

e. Kliniğin Google'daki arama pozisyonunun yükseltilmesi,

f. İris hastalık tanı yönteminin uygulamaya konulması,

g. Ücretsiz kursların verilmesi (Kang ve Li, 2013).

Bu çalışmadan görüldüğü gibi mavi okyanus stratejisi kliniğin odaklanması gereken hususları ortaya koymuştur.

Sağlık alanında uygulanan diğer bir mavi okyanus strateji örneği ise tıp fakültelerine yöneliktir. İsviçre'de Linköping Tıp Fakültesi yenilikçi ve başarılı bir üniversitedir. Yazarlar başarının nedenlerini daha iyi anlayabilmek için İsviçre' de Linköping Tıp Fakültesi eğitimini, geleneksel tıp eğitimi ile kıyaslayarak strateji yelkenini oluşturmuşlar ve üniversitenin mevcut durumunu mavi okyanus stratejinin altı prensibi açından değerlendirmişlerdir. Araştırma sonunda İsviçre'de Linköping Tıp Fakültesinin müfredatın farklı boyutlarında yaptığı azaltma, arttırma, eleme ve yaratma girişimleri ile sınırları aşabildiği ifade edilmektedir. Ayrıca mavi okyanus strateji araçlarının yeni değer eğrisi yaratmada kullanışlı olduğu görülmüştür (Savage ve Brommels, 2008).

Kamal ve Dionne-Odom (2016) ise palyatif bakım sektöründe olası mavi okyanusu bulduğunu öne sürmektedir. ABD'nde palyatif bakımın hızla gelişen bir sektör olduğunu ve gelecek yıllarda bu sektörün daha da artacağını ifade etmektedir. Ancak bu sektörün aile bireyleri tarafından hastalara verilen bakım olmaksızın devam etmesi halinde sağlık sistemi için ciddi bir sorun olacağını vurgulamıştır. Bu sorunun çözümü için bakım veren aile bireylerinin palyatif bakım sektöründeki "mavi okyanus" olabileceğini vurgulamakta ve bu aile bireylerine odaklanılması gerekliliğini ifade etmektedir.

\section{Tartışma ve Sonuç}

Mavi okyanus stratejisini uygulayan şirketler genellikle yeni müşterileri çekebilmektedirler. Ayrıca mavi okyanusu uygulayan şirketler farklılık ve düşük maliyete erişmeye çalışarak 
başarılı olabilirler. Bu sayede rakiplerine yönelik ekonomik bariyer yaratmakta oldukları düşünülmektedir (Chakrabarti, 2014).

Mavi okyanus stratejisi bir strateji aracı olarak yeni düşünceleri ortaya çıarmada ve fikirleri, değerlendirmeleri, analizleri organize etmede faydalı ve kullanımı kolay araçlara sahiptir. Mavi okyanus stratejisi birey ve organizasyon yönetimi tarafindan desteklenir ve uygun ortamda hayata geçirilirse, yenilikçi değer yaratma aracı olarak kullanılabilir (Ergen, 2011).

Mavi okyanus stratejisi uygulama kapsamı nedeniyle, yüksek ölçekte güvenilir bir strateji olarak tanımlanmaktadır. Yapılan literatür taramalarında birçok işletme tarafından kullanıldığı görülmektedir. Hatta bazı durumlarda mavi okyanus stratejisi diğer stratejiler ile kombine edilmiştir. Bu nedenle mavi okyanus stratejisi uygulama yönünden kullanışlı olarak ifade edilmektedir (Kabukin, 2014).

Mavi okyanus stratejisine yönelik yorumların tamamı olumlu değildir. Mavi okyanus stratejisine yönelik eleştiriler genellikle teori başarısının düşük olasılıklı olması üzerine toplanmıştır (Kabukin, 2014). Ayrıca mavi okyanus stratejisine yönelik diğer bir eleştiri ise işletme yöneticileri tarafından stratejinin tam olarak anlaşılmadığı yönündedir (Cengiz, 2013; Kirfi vd., 2013).

Bu stratejinin yaratıcıları ortaya koydukları teorinin tanımlayıcı bir araştırmaya dayandığını ifade etmektedirler. Yüksek performans için işletmelerin stratejiyi nasıl formüle edeceklerini veya yürüteceklerini adım adım gösteren belirli bir model bulunmamaktadır (Zemsky, 2015)

Mavi okyanus strateji teorisi sadece başarılı işletmelere odaklandığ ${ }_{1}$ ve mavi okyanus stratejisi başarının tek faktörü olmadığı göz önüne alındığında, mavi okyanus stratejisinin başarının anahtarı olup olmadığı sorusu gündeme gelmektedir (Nicolas, 2011). Bu kaygıyı destekler nitelikte Buisson ve arkadaşlarının (2010) yaptığı araştırmada mavi okyanus stratejisinin tüm değer inovasyon girişimlerini açılamada başarısız olduğunu ifade edilmektedir. Sayısız inovatif işletmenin başarılı olarak piyasada tutunabildiği gibi, çoğu inovatif işletmenin de arkadan gelen rakipleri tarafından yenildikleri tespit etmişlerdir. Bu nedenle mavi okyanus stratejisine yönelik olarak vaka çalışmalarının yapılması gerekmektedir (Nicolas, 2011). Ancak mavi okyanus stratejisine yönelik olarak yapılabilecek uygulama araştırmaları zaman alıcıdır (Čirjevskis vd., 2011). Bu nedenle bu stratejinin farklı sektörlerde uygulanabilirliğine yönelik araştırmalar sınırlıdır.

Mavi okyanus stratejisinin büyük ilgi toplamasına rağmen, "Bu okyanus gerçekten mavi mi? gerçekten piyasalarda mavi okyanuslar var mı?" soruları gündeme gelmektedir. Geçmişe baktığımızda 1990'ların başında telefon piyasasını Nokia Motorola'nın elinden almıştır. Bir benzerini Samsung Nokia'ya yapmıştır. Samsung sürekli olarak mavi okyanus stratejini uygulayarak yeni okyanuslar oluşturduğunu ifade etmektedir. Ancak Apple tasarımcisı Jonathan Ive yaklaşımlarını; "Hedeflerimiz oldukça basittir, daha iyi ürünler yapmak ve tasarımlamaktır. Çoğu rakibimiz farklı ürünler yapmakla ve farklı görünmekle ilgilenmektedir. Bence bunlar tamamen yanlış hedeflerdir" diyerek farklı bir görüş öne sürmektedir (Barwise ve Meehan, 2012).

Mavi okyanus stratejisi aldığ1 eleştirilere rağmen, öne sürüldüğünden beri yoğun ilgi toplamış ve birçok endüstri tarafından kullanılmıştır. Yöneticilere yönelik olarak kullanımı kolay araçlar sunması nedeni ile birçok işletme tarafından denenmiştir. Farklı endüstrilerde başarılı sonuçlar almıştır. Ancak günümüzde okyanusların uzun süre mavi kalması mümkün olmadığı için rekabet her zaman varlığını ve önemini koruyacaktır. 
Sağlık hizmetleri endüstrisinde uygulamaları oldukça sınırlıdır. Ancak diğer endüstrilerde başarılı uygulamalarından yola çıkarak, uluslararası rekabetin yoğun olduğu sağlık turizminde kullanışlı olabileceği değerlendirilmektedir. Ayrıca kırmızı okyanus kurallarının daha yoğun olduğu özel sağlık hizmeti sunan organizasyonlar tarafından da kullanılabileceği düşünülmektedir. Uzmanlaşmanın çok yoğun ve hizmet maliyetlerinin oldukça yüksek olduğu sağlık hizmet organizasyonlarının gereksiz olarak odaklandığı faktörlerin belirlenmesinde oldukça kullanışlı olabileceği değerlendirilmektedir.

Türkiye gibi sağlık hizmet sunum finansmanın büyük kısmının Genel Sağlık Sigortası, vergilerden karşılanan ülkelerde kamu sağlık hizmet sektöründeki rekabet oldukça sınırlıdır. Rekabetin sınırlı olması kamu sağlık organizasyonların yeni talep yaratma isteklerini olumsuz etkileyeceğinden dolayı, bu tür kamu sağlık sistemlerinde mavi okyanus uygulamalarının yeni değer yaratma potansiyelinin az olduğu değerlendirilmektedir.

Sağlık personelinin otonom çalışması ve örgüt kültürünün sağlık organizasyonlarında daha güçlü olduğu göz önüne alındığında, mavi okyanus stratejisinin sağlık hizmet organizasyonlarında uygulanmasında organizasyonel engellerin daha yoğun yaşanacağı düşünülmektedir. Bu sınırlılıklara rağmen, literatürde mavi okyanus stratejisinin sağlık hizmet sektöründe yapılan sınırlı araştırmalar (Ahuja, 2010; Kang ve Li, 2013; Orros ve Howell, 2008), bu stratejisinin sağlık sektöründe uygulanabilme potansiyelinin olduğu değerlendirilmektedir. Ancak mavi okyanus stratejinin sağlık sektöründe uygulanabilirliğine ve başarısına yönelik ileri çalışmalara ihtiyaç olduğu düşünülmektedir.

\section{Kaynakça}

Ahuja, L. (2010). Study of For-Profit Family Physician Based Health Models Nationwide Primary Healthcare Pvt. Ltd. Bangalore, India.

Barutçu, Ş. (2014). The Usage of Blue Ocean Strategy in City Marketing; Case of Bodrum. Yeditepe University Institute of Social Science, Department of Integrated Marketing Communication Management Master Thesis, İstanbul.

Barwise, P. ve Meehan, S. (2012). Innovating Beyond Blue Ocean. Market Leader, Quarter 4.

Buisson, B. ve Silberzahn, P. (2010). Blue Ocean or Fast-Second Innovation? A FourBreakthrough Model to Explain Successful Market Domination. International Journal of Innovation Management, 14(03), 359-378.

Cengiz, S. (2013). Çağdaş yönetim teorileri altı sigma, kriz yönetimi, mavi okyanus ve kaos teorisinin iletme performansları üzerinde etkileri, Türkiye'den bir ampirik çalışma. Beykent Üniversitesi Sosyal Bilimler Enstitüsü İşletme Yönetimi Bilim Dalı Yüksek Lisans Tezi, İstanbul.

Chakrabarti, M. (2014). Blue Ocean Marketing Strategy (BOMS): An Overview. AbhinavInternational Monthly Refereed Journal Of Research In Management \& Technology (Online ISSN 2320-0073), 3(6), 68-73.

Čirjevskis, A., Homenko, G. ve Lačinova, V. (2011). How to Implement Blue Ocean Strategy (BOS) in B2B Sector. Business, Management and Education, 9(2), 201-215. 
Collaboration Health Care. (2008). Exploring Blue Oceans in 2008, Aligning Ideas with Execution to Improve Health Care Today, 1 (3), 1-2.

Dehkordi, G. J., Rezvani, S. ve Behravan, N. (2012). Blue Ocean Strategy: A Study Over A Strategy Which Help the Firm to Survive from Competitive Environment. International Journal of Academic Research in Business and Social Sciences, 2(6), 477.

Eboreime, O. F., Gbandi, E. C., Zaini, A., Hadiwidjojo, D., Rohman, F., Maskie, G., Onukwuli, A. G., Akam, U. G., Onwuka, E. M. ve Omunjalu, B. S. (2014). Blue-Ocean Strategy: The Strategic Logic of High Growth for Small and Medium Enterprises in Nigeria. Journal of Management Development, 22, 863-880.

Ergen, A. (2011). Stratejik Düşünce Yaratma: Mavi Okyanusa Yelken Açma. Pazarlama ve Pazarlama Araştırmaları Derneği Dergisi, 4(7).

Haavisto, V. (2005). Creative Forces Make Blue Oceans-A Study of Creativity Accompanying Industrial Strategy Making. Taideteollinen korkeakoulu. Joining Forces. Saatavissa: http://www2. uiah. fi/joiningforces/papers/Haavisto. pdf.

Kabukin, D. (2014). Reviewing the Blue Ocean Strategy. Is the Blue Ocean Strategy valid and reliable? University of Twente, Business Administration Innovation \& Entrepreneurship Master Thesis.

Kamal, A. H. ve Dionne-Odom, J. N. (2016). A Blue Ocean Strategy for Palliative Care: Focus on Family Caregivers. Journal of pain and symptom management, 51(3), e1-e3.

Kang, S. ve Li, D. (2013). Blue Ocean strategic planning of acupuncture clinics' business in Copenhagen-adapt "Jiankang Clinic" as a case study. Rosklide University.

Kim, W. C. (2008). Blue Ocean Strategy challenges companies to make competition irrelevant. Academy Magazine(Autumn), 18-21.

Kim, W. C. ve Mauborgne, R. (2004). Blue ocean strategy. Harvard Business Review.

Kim, W. C. ve Mauborgne, R. (2005a). Value innovation: a leap into the blue ocean. Journal of Business Strategy, 26(4), 22-28.

Kim, W. C. ve Mauborgne, R. (2005b). Blue ocean strategy: from theory to practice. California management review, 47(3), 105-121.

Kim, W. C. ve Mauborgne, R. (2005c). Blue Ocean Strategy, Expanded Edition: How to Create Uncontested Market Space and Make the Competition Irrelevant: Harvard Business Review Press.

Kim, W. C. ve Mauborgne, R. (2009). How strategy shapes structure. Harvard Business Review, 87(9), 72-80.

Kirfi, M. M. W., Ajadi, I. A. ve Aliyu, A. A. (2013). Blue Ocean Strategy and the Future of Public Sector: A Study of Health Insurance Reforms Implementation in Nigeria. International Journal of Business and Management Invention, 2(5), 67-74.

Lainos, I. (2011). Red Ocean vs Blue Ocean Strategies. University of Piraeus Master Thesis.

Leavy, B. (2005). Value pioneering - how to discover your own "blue ocean": interview with W. Chan Kim and Renée Mauborgne. Strategy \& Leadership, 33(6), 13-20. 
Nasrollahzadeh, T., Marsono, A. K. ve Tap, M. (2014). Applying the Principles of Blue Ocean Strategy in Supply Chain Management on Corporate Performance. International Journal of Innovative Technology and Exploring Engineering (IJITEE), 4(5), 1-4.

New Jersey Health Department (2012). Cardiac Surgery in New Jersey, Health Care Quality Assessment, Health Care Quality Assessment Office of Policy and Strategic Planning.

Nicolas, G. (2011). The evolution of strategic thinking and practices: Blue Ocean Strategy.

O'Gorman, P. (2008). Wii: Creating a Blue Ocean the Nintendo Way. Palermo Business Review(April).

Orros, G. C. ve Howell, J. (2008). Creating value through integrated ERM for healthcare insurers in Europe. Paper presented at the ERM Symposium, Chicago, Illinois. Available at: http://www. ermsymposium. org/2008/pdf/papers/Orros. pdf.

Parvinen, P., Aspara, J., Hietanen, J. ve Kajalo, S. (2011). Awareness, action and contextspecificity of blue ocean practices in sales management. Management Decision, 49(8), 12181234.

Rawabdeh, I., Raqab, A., Al-Nimri, D. ve Haddadine, S. (2012). Blue Ocean Strategy as a Tool for Improving a Company's Marketing Function: The Case of Jordan. Jordan Journal of Business Administration, 8(2), 390-407.

Savage, C. ve Brommels, M. (2008). Innovation in medical education: how Linkoping created a Blue Ocean for medical education in Sweden. Med Teach, 30(5), 501-507.

Sheehan, N. T. ve Vaidyanathan, G. (2009). Using a value creation compass to discover "Blue Oceans". Strategy \& Leadership, 37(2), 13-20.

Štverková, H., Červinka, M. ve Humlová, V. (2012). The Impact of Blue Ocean Strategy in Lowcost Transport. Paper presented at the 2012 International Conference on Traffic and Transportation Engineering (ICTTE 2012), Singapore.

Tabari, M., Ziabari, M., Radmard, M. ve Radmard, M. (2014). The role of a blue ocean strategy on performance evaluation. Management Science Letters, 4(8), 1611-1618.

Ülgen, H. ve Mirze, S. K. (2013). İşletmelerde stratejik yönetim: Beta Basım Yayın, İstanbul.

Welch, S. J. ve Edmondson, B. (2011). Commentary: Applying Blue Ocean Strategy to the foundation of Accountable Care. Am J Med Qual, 27(3), 256-257.

Zemsky, P. (2015). Blue Ocean Strategy. Salamander Insead Alumnı Magazıne(February). 